\title{
QUALITY DETECTION OF HEATING CORN OIL USING VISIBLE AND INVISIBLE LIGHT
}

\author{
H. E. Hassan ${ }^{1} \quad$ H.A. Badawy ${ }^{2}$
}

ABSTRACT

The corn oil was heated at $180^{\circ} \mathrm{C}$. for six durations $(3,6,9,12,15$, and $18 \mathrm{hrs}$ ) to measure some optical, physical and chemical properties of oil with exposure by visible and invisible lights. Three light regions, ultraviolet (200-400nm), visible light (400-700nm), and near infrared (700-900nm) were used in the present work. The obtained results are summarized as follows: (1) The highest transmission light percentages were 94.89, 88.57 and $33.17 \%$ for using wavelengths of $900 \mathrm{~nm}$ (IR), 700 $\mathrm{nm}(V I S)$ and $400 \mathrm{~nm}(U V)$, respectively.; (2) The highest absorption light percentages from heated corn oil were 0.09, 0.12, and $1.26 \%$ at using $900 \mathrm{~nm}$ (IR), $700 \mathrm{~nm}$ (VIS), and $400 \mathrm{~nm}$ (UV) wavelengths.; (3) The wavelength (400 nm) of $U V$ is the highest measure of absorption light of corn oil. Meanwhile, $900 \mathrm{~nm}$ of IR and $700 \mathrm{~nm}$ of VIS are the highest measure of transmission light can be used to measure corn oil quality.; (4) The heating times were increased from 3 to 18 hrs lead to increase oxidized fatty acid, Polemer, acid value, peroxide value, and reflective index, while, the iodine value and viscosity were decreased compare with control sample.; and (5) The corn oil will start deterioration after $15 \mathrm{hrs}$ of heating time whereas oxidization fatty acid more than $1 \%$ at transmission light percentages $13.69 \%$ and $12.20 \%$ of wavelength 900 $\mathrm{nm}$ (IR) and 700 (VIS) and at absorption percentage $1.06 \%$ of wavelength $400 \mathrm{~nm}(\mathrm{UV})$.

\section{INTRODUCTION}

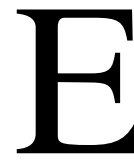

dible oils extracted from plant sources are important in foods and in various other industries such as cosmetics, pharmaceuticals and lubricants. Markley (1990) mentioned that, in general, the refractive indices of natural fats and oils are related to their average degree of unsaturation in an approximately linear way. The relationship between refractive index and the iodine, acid, and saponification values is somewhat more complex.

1- Assoc. Prof., Nat. Inst. of Laser Enhanced Sc. (NILES), Cairo Univ., Egypt.

2- Prof. Dr., Food Tech. Res. Inst., Agr. Res. Center, Giza, Egypt. 
Eisenberg et al. (2000) mentioned that the light in the array is guided by individual channels so narrow beams do not experience widening caused by traditional diffraction. Spreading of the beam occurs due to the coupling between adjacent wave guides. The properties of such a discrete diffraction are different from diffraction in uniform media. The output distribution of power depends on the coupling coefficient. The diffraction can be managed from normal to zero and anomalous depending on the beam incidence angle.

Almeida and Regitano (2000) said that soybean oil exposed to fluorescent light (8,370 Lux), in a rectangular box of $80 \mathrm{~cm}$ length $x 35 \mathrm{~cm}$ height $\times 60 \mathrm{~cm}$ width, provided with six of $20 \mathrm{~W}$ fluorescent light bulbs, displayed 3 above and 3 under the samples, presented increasing peroxide value and absorptions at 232 and 270nm., to detect oil quality.

Buning (2003) mentioned that the visible/near infra red light (VIS/NIR) reflectance spectroscopy has shown a lot of advantages over traditional chemical methods. It is a non-destructive fast method with high precision that requires minimum or no sample preparation. It allows the elimination of hazardous reagents required in chemical wet methods and no waste is produced during the analysis.

Christodoulides et al. (2003) reported that the influence of light intensity on the refractive index distribution appearing in non-linear materials makes it possible to control optically discrete diffraction strength, which leads to the propagation of self-trapped beams called discrete solutions.

Can and Delibas (2004) mentioned that the mass temperature and relative humidity as storage conditions and moisture content due to its effect on quality criteria, oil content and free fatty acidity as sunflower quality criteria were determined on the sample collected from each stores during the storage. $3 \times 4 \times 3$ factorial experimental design as randomized plot design was applied.

Cozzolino et al. (2005) reported that in the past few years near infra red spectrum (NIRS) has been widely used in the analysis and quality assessment of fats and oils. Successful applications of (NIRS) for determination of trans content, peroxide value (PV), iodine value and degree of unsaturation, and free fatty acid (FFA) content of oils. 
Robert et al. (2006) said the dry kernels of grain corn contain low levels of oil (about 4\%), but most of the oil is contained in the embryo or "germ" portion of the kernel. Corn germ obtained from wet mills usually contains about 40-50\% oil, and corn germ from dry mills usually contains about 20-25\% oil (both yields expressed on a dry weight basis).

Star et al. (2005) observed that the propagation of light in an optically induced wave-guide array in biased photo refractive media with a quadratic electro-optic effect is investigated numerically with the beam propagation method. The refractive index distribution of the array is induced by two coherent plane waves interfering in a guiding layer in a photo refractive multiple quantum well (MQW) planar wave-guide.

Abd El-Wahab (2006) mentioned that the edible oils are the least food products self-sufficient in Egypt, as its self-sufficiency rate falls in range of $11-14 \%$. Most studies have shown that production of principal oil crops face serious technical and economic problems, inflicting promotion if not causing drawbacks.

Hassan and Badawy (2006) found that deterioration of sunflower oil was started after 14 hours of heating at the light intensity 400 lux of transmission; and the laser Helium - Neon with wavelength $543.5 \mathrm{~nm}$ and power $4 \mathrm{mw}$ can be used a detector for measuring oil deterioration as chemical and physical properties of oil.

Amin et al. (2007) mentioned that for both economic and technical reasons, maize presents the highest potentials for narrowing the edible oils production gap in Egypt. The government's tendency to size production of wheat-maize mix bread, which represents the principal competitor. Marketed maize, after satisfaction of rural households' direct needs would help doubling the self-sufficiency rate of edible oils.

Lukesov et al. (2009) reported that the peroxide value was taken as a measure for the degree of oxidation during the microwave heating of oil samples. Accordingly, the rates of peroxide formation in the tested oils are arranged in following ascending order: rapeseed oil > corn oil > soybean oil $\sim$ sunflower oil. It was observed that the peroxide value of these oils increased gradually as microwave heating is progressing till they reached the highest values. 


\section{Objective}

The aim of this study are: (1) determined some physical, and chemical properties of heated corn oil, and (2) study of optical properties and select suitable wavelength from ultraviolet, visible and infrared lights to quality detection of corn oil.

\section{MATERIAL AND METHODS}

Measurement of the optical characteristics of heated corn oil were done at in the Laboratory of Laser Applications at the National Institute of Laser Enhanced Science, Cairo University, to select suitable wavelength from visible (VIS) and invisible lights [Ultraviolet (VU) and Infrared (IR) wavelengths] to measure corn oil quality and the experiments of physical and chemical analysis were done in Oils Department, Food Technology Institute, Agricultural Research Center, Giza.

Sample preparation: Corn oil was obtained from Department of Oils, Food Technology Institute. The corn oil was heated at $180{ }^{\circ} \mathrm{C}$. for six durations $(3,6,9,12,15$, and $18 \mathrm{hrs}$.) to measure deterioration of oil and exposure to visible and invisible lights to determine optical characteristics of oils at different wavelengths. Also, physical and chemical properties were measured. All measurements were done at room temperature.

Optical properties: The light beam passes through sample cell of oil. The transmission of incident beam and the absorption percentages of corn oil were measured in the spectrophotometer with a 200 to $900 \mathrm{~nm}$ wavelengths range, in order to determine suitable wavelength to measure quality of corn oil. Diagram of beam, which passes through the spectrophotometer and photo it is shown in (Fig .1).

Setup: The experimental setup consisted of spectrophotometer; visible, invisible lights, filter, lenses, holders, quartz cuvette, and personal computer (PC).

Spectrophotometer: Spectrophotometer is a laboratory grade doublebeam UV/VIS spectrometer. The instrument can be operated through the PC. Specifications of spectrophotometer are illustrated in Table (1).

Lamps: The light source for the UV wavelengths range is a Deuterium lamp, this lamp emits light from $190 \mathrm{~nm}$ to $380 \mathrm{~nm}$ wavelengths. Meanwhile, light source for the visible and NIR wavelengths range are a 
Tungsten lamp; this lamp emits light from $370 \mathrm{~nm}$ to $1100 \mathrm{~nm}$ wavelengths.

Light types: Three lights, ultraviolet with wavelengths from 200 to 400 $\mathrm{nm}$, visible light with wavelengths from 400 to $700 \mathrm{~nm}$, and near infrared with wavelengths from 700 to $900 \mathrm{~nm}$ were used in the present work as a light source.
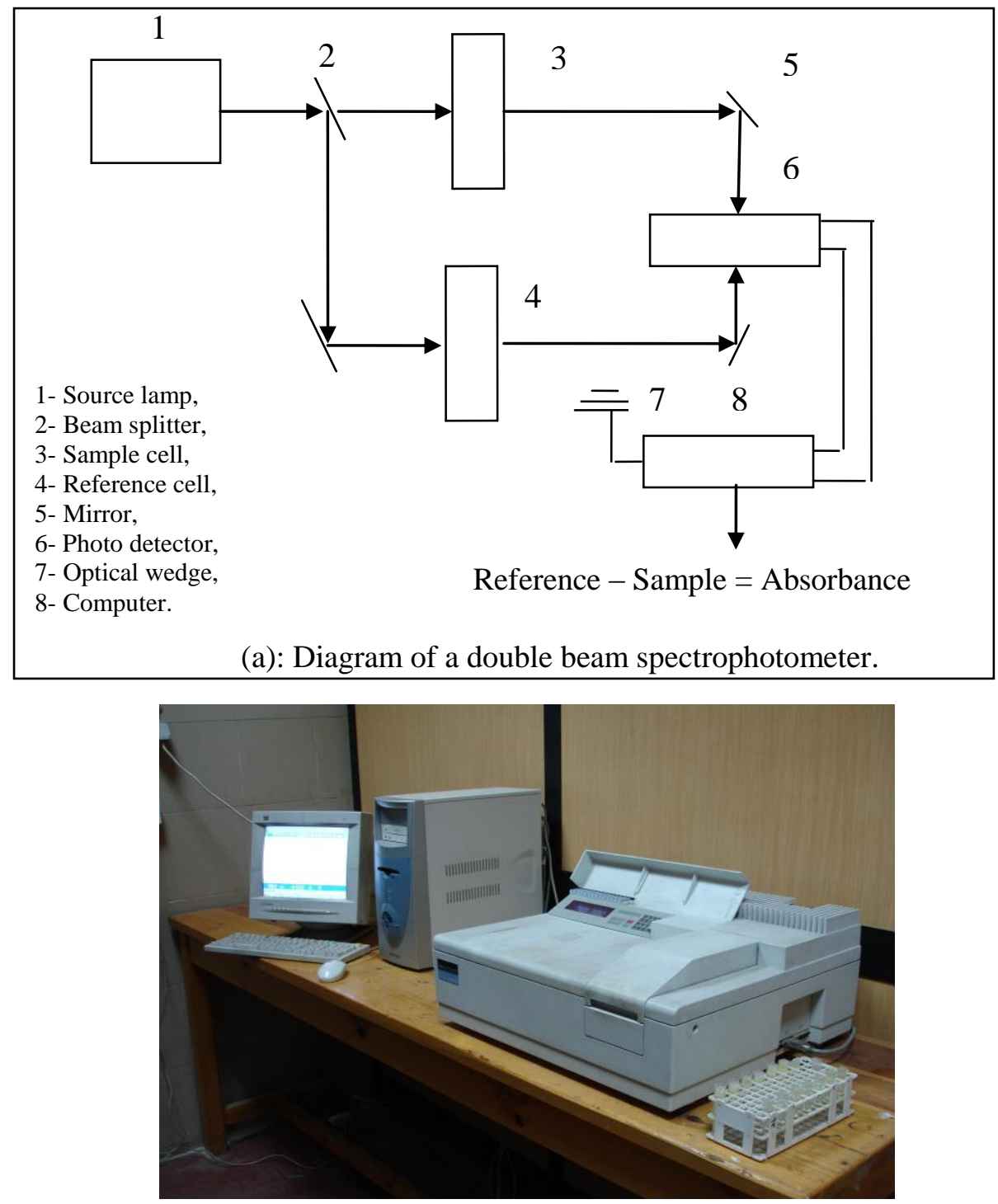

(b): Photo of spectrophotometer.

Fig. (1): Diagram of double beam and photo of spectrophotometer. 
Table (1): Specifications of Perkin Elmer Lambda 40 UV/VIS spectrophotometer.

\begin{tabular}{|l|l|}
\hline Items & \multicolumn{1}{|c|}{ Specifications } \\
\hline Model: & Lambda 40 \\
\hline Made & USA \\
\hline Wavelength Range: $(\mathrm{nm})$, & $190-1100$ \\
\hline Wavelength Accuracy: $( \pm \mathrm{nm})$ & 1 \\
\hline Resolution: $(\mathrm{nm})$ & 0.5, \\
\hline Max Scan Speed: $(\mathrm{nm} / \mathrm{min})$ & 2800, \\
\hline Monochromator: & 1440 ruled line Grating, \\
\hline Detector & Silicon diode \\
\hline Slit Width: & $2.0 \mathrm{~nm}$, \\
\hline Grating, mm & Holographic, concave with grating 1053 lenses \\
\hline Light sources: $6 \mathrm{~V} / 20 \mathrm{~W}$ & Deuterium and Tungsten- Halogen Lamps \\
\hline Dimensions: LxWxH" & $26 \times 9 \times 22$ \\
\hline Mass: & $26 \mathrm{~kg}$. \\
\hline
\end{tabular}

Lens: The lens receives the light from both lamps (Deuterium and Tungsten lamps) and collimates it, then the beam passes through the sample.

Shutter: The shutter is electromechanically actuated; it opens and allows light to pass through the sample for measurements. It closes to limit exposure of sample to light.

Stray Light Filter: Sample intensity spectra are measured without straylight filter in the light beam. Without the filter, the intensity spectrum over the whole wavelength range from $190-1100 \mathrm{~nm}$ is measured. The stray-light filter is a blocking with $50 \%$ at $420 \mathrm{~nm}$, and the light place of this filter was measured below $400 \mathrm{~nm}$.

Quartz sample cells (cuvette): Sample cells with quartz face plates are required to use the full 190 to $1100 \mathrm{~nm}$ wavelength range, Two optical windows with $1 \mathrm{~cm} / 10 \mathrm{~mm}$ path length; outer dimensions of $12.4 \times 12.4 \times 45 \mathrm{~mm}$ for standard fit and sample volume of $3.5 \mathrm{ml}$.

Computer: Utilized the software, which shows the results of optical analysis of oils (Agilent Chem. Station Software). 


\section{Physical and chemical characteristics of corn oil:}

The following physical and chemical characteristics were measured according to the methods described in the (A.O.A.C., 1990): reflectivity index, viscosity, oxidized fatty acids, peroxide value, acid value, and iodine number.

\section{RESULTS AND DISCUSSION}

Some physical, chemical and optical properties of heated corn oil samples were studied at different heating times as follow:

Fig. (2) showed that the transmission light percentages of ultraviolet (UV), visible (VIS), and infrared (IR) lights with different wavelengths, which passed through heated corn oil. It was noticed that the transmission light percentages were decreased by using infrared lights from 700 to $900 \mathrm{~nm}$, visible lights from 400 to 700 $\mathrm{nm}$, and ultraviolet lights from 200 to $400 \mathrm{~nm}$ wavelengths. The highest light transmission percentages were found of $94.89,88.57$ and $33.17 \%$ for using wavelengths of $900 \mathrm{~nm}$ (IR), $700 \mathrm{~nm}$ (VIS) and $400 \mathrm{~nm}$ (UV), respectively. The transmission light percentages were found directly proportional with wavelength. Therefore, it was possible to use $900 \mathrm{~nm}$ (IR) to $700 \mathrm{~nm}$ (VIS) wavelengths as measuring quality of heated corn oil but, it is preferred to use about $700 \mathrm{~nm}$ wavelength as visible light. So, it is possible using experimental setup for measuring oil quality and select visible light with wavelength from 600 to $700 \mathrm{~nm}$

Fig. (3) illustrated that the absorption light percentages of ultraviolet, visible, and infrared lights with different wavelengths from heated corn oil. It was showed that the absorption light percentages were decreased from 700 to 900 , from 400 to 700, and from 200 to $400 \mathrm{~nm}$ wavelengths for IR, VIS, and UV lights, respectively. Generally, the absorption light percentages were increased by the decreases wavelengths.

Therefore, the highest absorption light percentages from heated corn oil were $0.09,0.12$, and $1.26 \%$ at using $900 \mathrm{~nm}$ (IR), $700 \mathrm{~nm}$ (VIS), and $400 \mathrm{~nm}$ (UV) wavelengths. The highest absorption light percentage was obtained by using UV light wavelength. It can be used to measure corn oil quality. It was found that the absorption light percentage inverse proportionally with wavelength. It was found that there was inverse 
relationship between transmission and absorption light percentages from oil at different wavelengths.

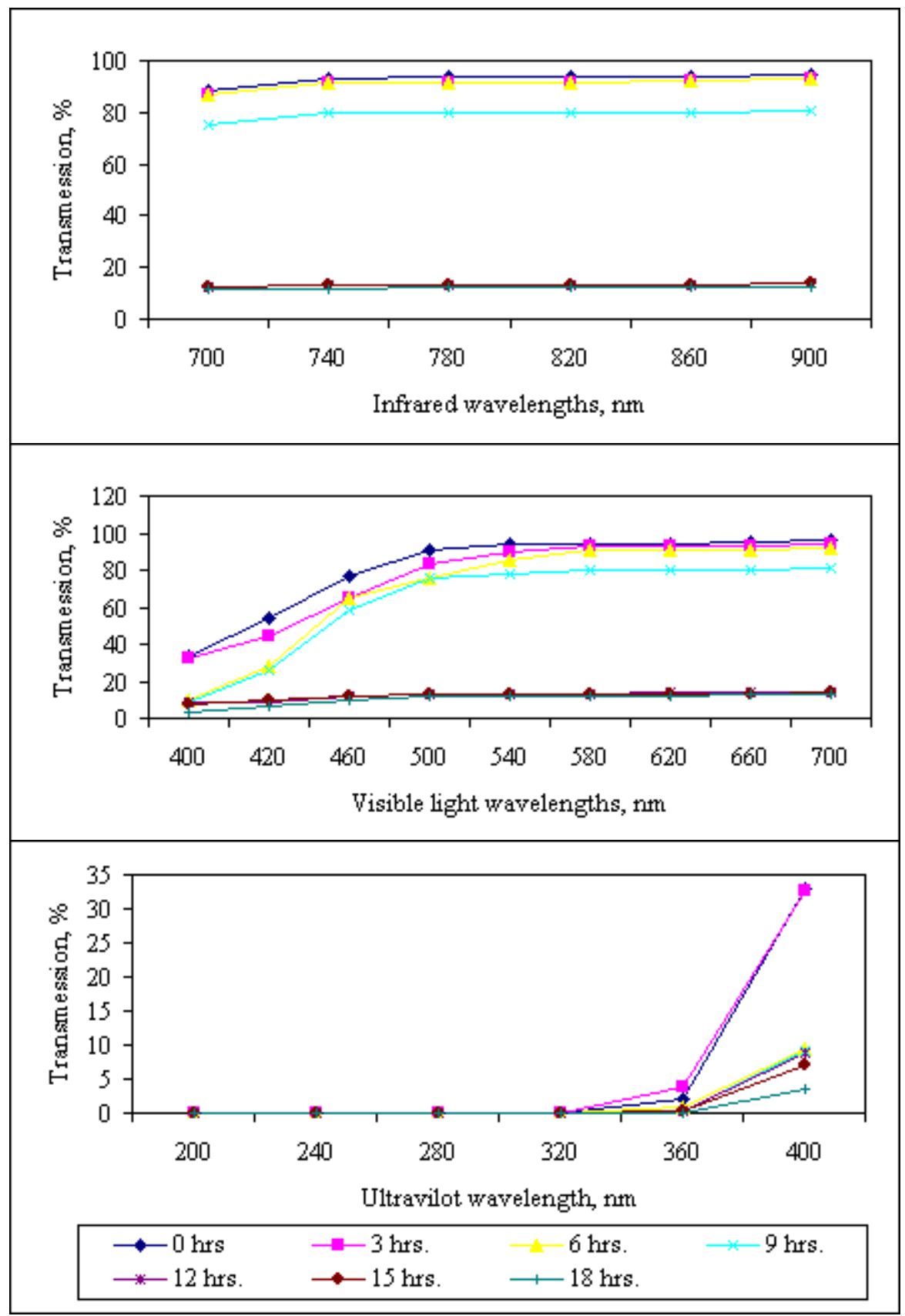

Fig. (2): Transmission light percentages through heated corn oil at different wavelengths. 


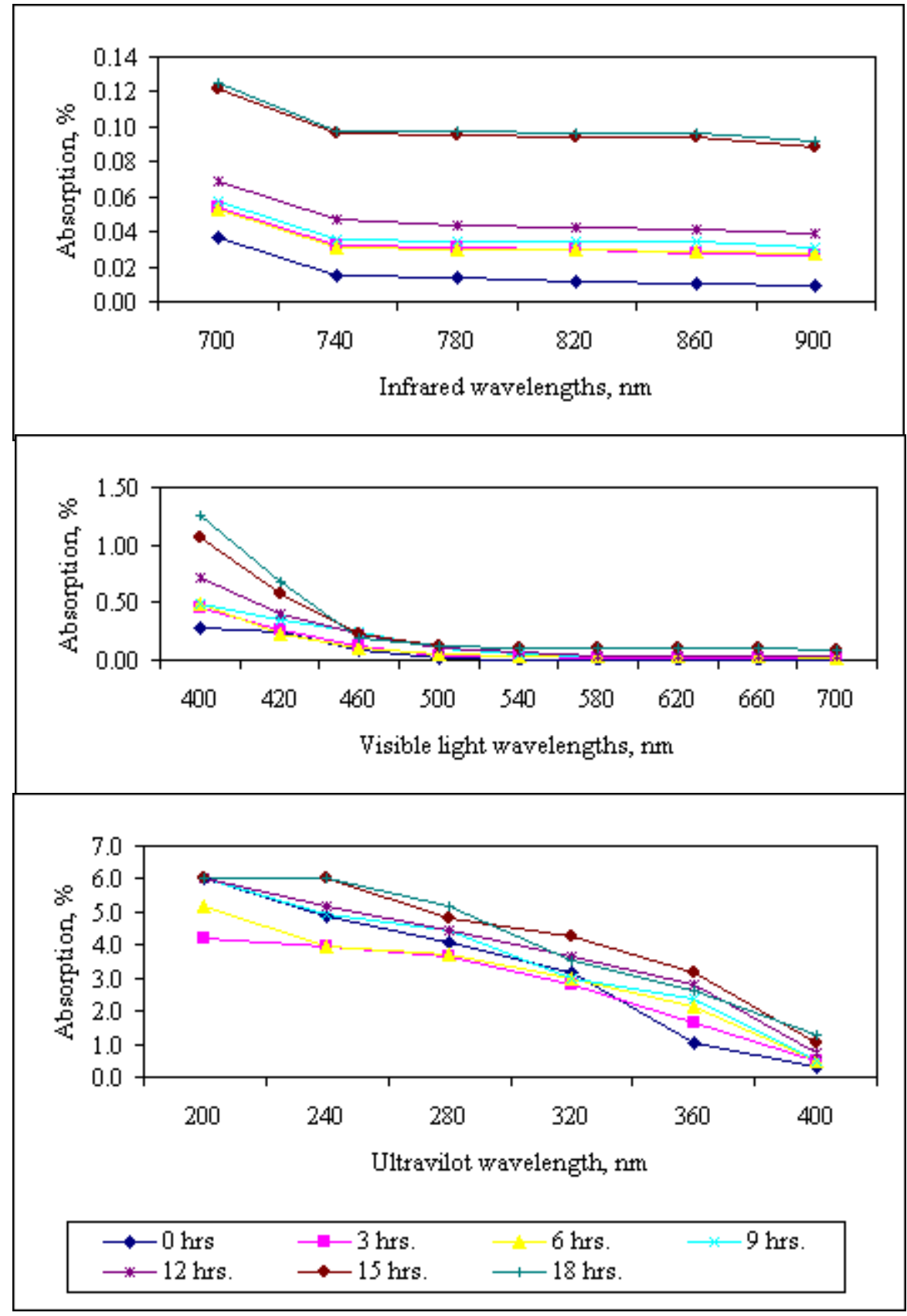

Fig. (3): Absorption light percentages from heated corn oil at different wavelengths. 
Fig. (4) indicated that the transmission and absorption light percentages from heated corn oil at using high wavelength of ultraviolet, visible, and infrared regions. Generally, the absorption light percentages were decreased by increasing the heating time from 3 to $18 \mathrm{hrs}$ at 200, 700 and $900 \mathrm{~nm}$. Meanwhile, the transmission light percentages were increased.

This mean that there was inverse relationship between the absorption light percentage and heating time of oil. Also, there was direct relationship between the transmission light percentage and heating time of oil

Also, the same figure showed that the absorption light percentages were increased from 0.28 to $1.26 \%$, from 0.03 to $0.12 \%$, and from 0.01 to $0.09 \%$ for UV, VIS, and IR regions, respectively with increasing heating time from 3 to $18 \mathrm{hrs}$. But, the transmission light percentages were decreased from 94.89 to $12.57 \%$, from 88.57 to $11.62 \%$, and from 33.07 to $3.55 \%$ at same heating time. From these results, it was found that at wavelength $(400 \mathrm{~nm})$ of UV gave the highest absorption of light for measuring corn oil quality. Also, at $900 \mathrm{~nm}$ of IR and $700 \mathrm{~nm}$ of VIS gave the highest transmission of light for measuring corn oil quality.

Figs. (5) and (6) showed that the effect of heating time on some chemical and physical characteristics of corn oil compare with control sample. It was noticed that oxidized fatty acid (OFA), Polemer $(\mathrm{P})$, acid value $(\mathrm{AV})$, peroxide value $(\mathrm{PV})$, and reflective index (RI) were increased from 0.29 to $1.82 \%$, from 0.49 to $1.58 \%$, from 0.56 to $1.89 \mathrm{mg}$ $\mathrm{KOH} / \mathrm{g}$, from 10.5 to $25.12 \mathrm{meq} \mathrm{O} / \mathrm{kg}$, and from 1.4732 to $1.4759 \mathrm{n}$, respectively with increase heating times from 3 to $18 \mathrm{hrs}$ of corn oil. The corn oil will start deterioration after 15 hours of heating time whereas oxidization fatty acid more than $1 \%$ according to A.O.A.C., (1990).

Meanwhile, the iodine value (IV) and viscosity (V)were decreased compare with control sample from 127.2 to $115 \mathrm{~g} \mathrm{I}_{2} / 100 \mathrm{~g}$ and from 63 to 158 C.P., at uses heating times of corn oil from 3 to 18 hrs. That mean, the changing in heating time of corn oil are changing of physical and chemical characteristics which, lead to increase absorption light percentages of UV light, from 0.28 to $1.26 \%$. While, the decreases of 
transmission light percentages of IR light from 94.89 to $12.57 \%$, and VIS light from 88.57 to $11.62 \%$.

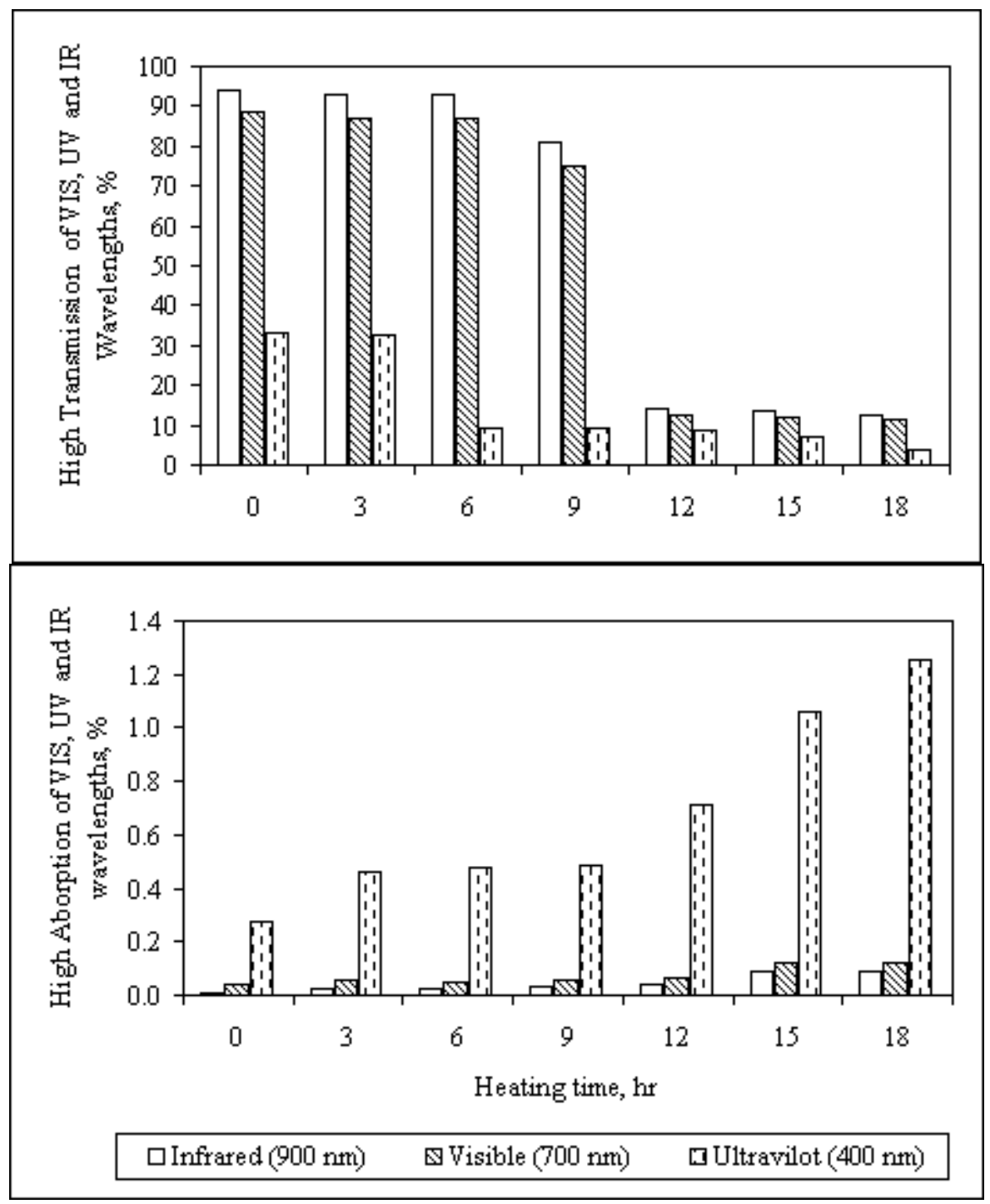

Fig. (4): High transmission and absorption light percentages through heated corn oil at wavelengths of Ultraviolet, Visible and Infrared . 


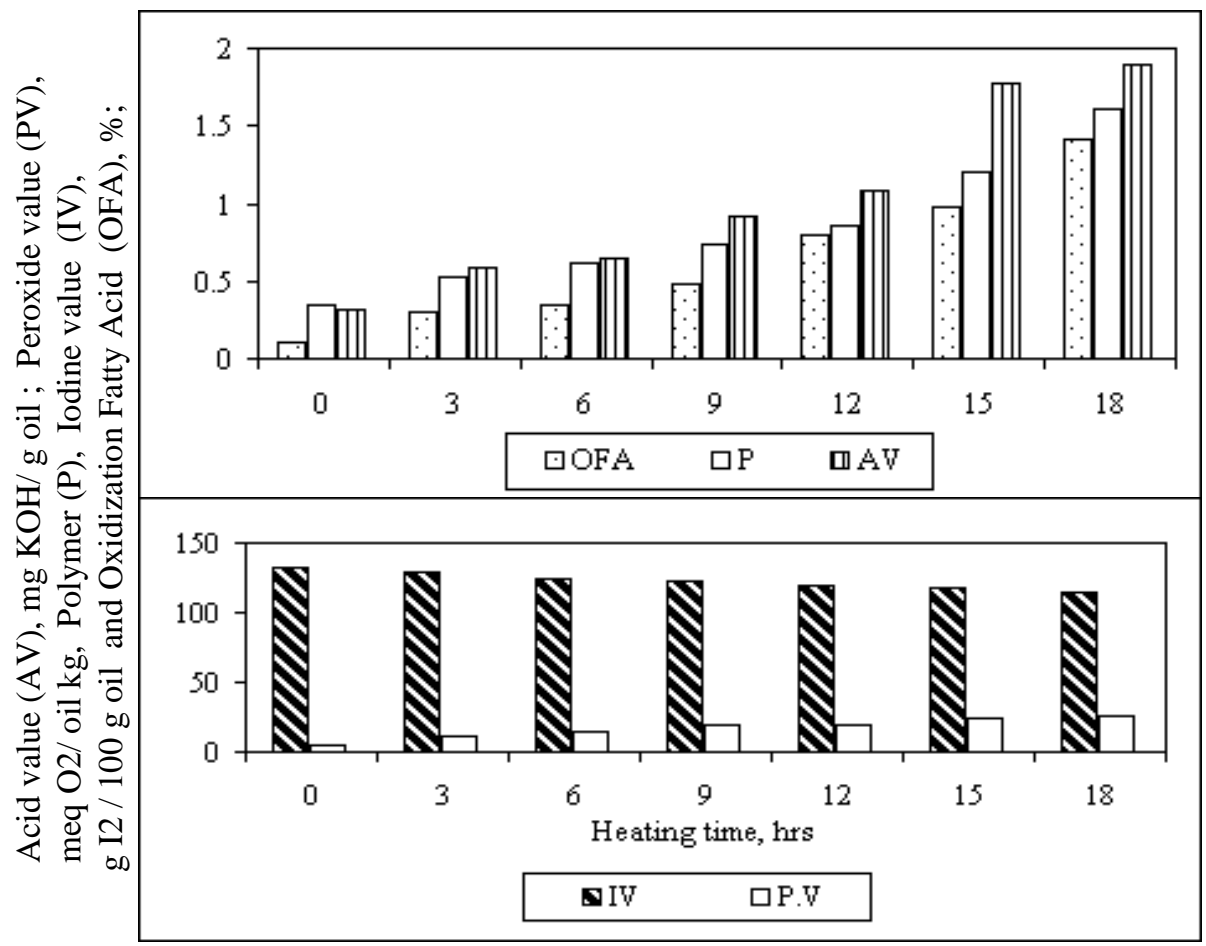

Fig. (5): Effect of heating time on some chemical properties of corn oil .

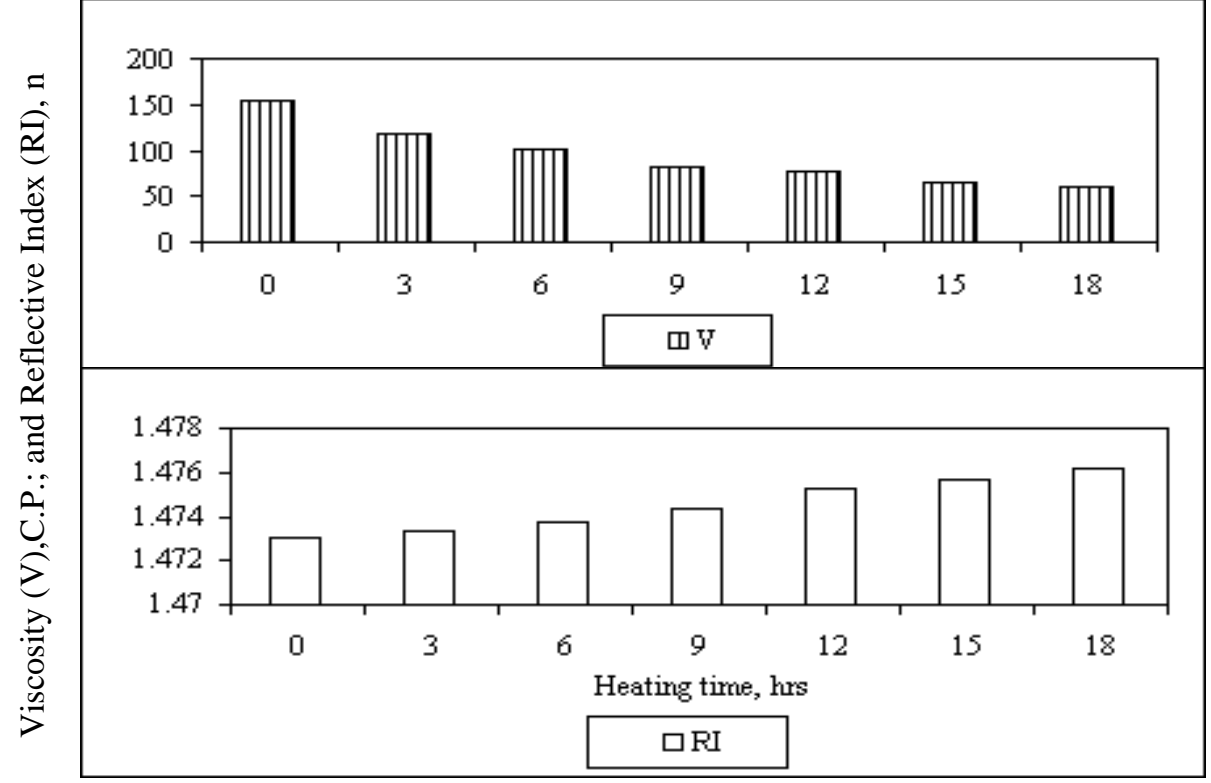

Fig. (6):Effect of heating time on some physical properties of corn oil . 


\section{CONCLUSION}

The obtained results were summarized as follow:

1- The highest transmission light percentages were 94.89, 88.57 and $33.17 \%$ for using wavelengths of $900 \mathrm{~nm}$ (IR), $700 \mathrm{~nm}$ (VIS) and $400 \mathrm{~nm}$ (UV), respectively.

2- The highest absorption light percentages from heated corn oil were $0.09,0.12$, and $1.26 \%$ at using $900 \mathrm{~nm}$ (IR), $700 \mathrm{~nm}$ (VIS), and $400 \mathrm{~nm}$ (UV) wavelengths.

3- The wavelength ( $400 \mathrm{~nm}$ ) of $\mathrm{UV}$ is the highest measure of absorption light of corn oil. Meanwhile, $900 \mathrm{~nm}$ of IR and $700 \mathrm{~nm}$ of VIS are the highest measure of transmission light can be used to measure corn oil quality.

4- The heating times were increased from 3 to $18 \mathrm{hrs}$ lead to increase oxidized fatty acid, polemer, acid value, peroxide value, and reflective index, while, the iodine value and viscosity were decreased compare with control sample.

5- The corn oil will start deterioration after $15 \mathrm{hrs}$ of heating time whereas oxidization fatty acid more than $1 \%$ at transmission light percentages $13.69 \%$ and $12.20 \%$ of wavelength $900 \mathrm{~nm}$ (IR) and 700 (VIS) and at absorption percentage $1.06 \%$ of wavelength $400 \mathrm{~nm}$ (UV).

\section{REFERENCES}

Abd El-Wahab, A.S. (2006). "Egypt/Sudan Agricultural Integration and Impact Upon Food Securing in Edible Oils for Both Countries". 14th Con. Agr. Econ.,: 20-21.

Almeida, D. R.F. and M.A.B.D. Regitano. (2000). Antioxidant activity of rosemary and oregano ethanol extracts in soybean oil under thermal oxidation. Ciênc. Tecnol. Aliment. 20 (2): 24-32.

Amin I. A., F. A. Shafik, and N. Y. Soliman. (2007). Production Expansion Potentials for Edible Corn Oil in Egypt. National Research Centre, Egypt. INSInet Publication. Journal of Applied Sciences Research, 3(1): 50-55, 2007

AOAC (1990). Official Methods of Analysis, 15 th Ed., Arlington, VA , pp 951- 986. 
Buning, P. H. (2003). Analysis of Water in Food by Near Infrared Spectroscopy. Food Chemistry. 82: 107-115.

Can, B. S. and L. Delibas. (2004). Storing Sunflower Seeds and Quality Losses During Storage, Trakya Univ., Tekirdag Agricultural Faculty, Farm Structure and Irrigation Dept, Journal of Central European Agriculture, 5 (4): 239-250.

Christodoulides, D.N.; F. Leder; and Y. Silberg. (2003). Discrediting light behavior in linear and nonlinear wave-guide lattices I, Nature 422,817

Cozzolino, D. I., M. A. Chree and J. R. Scaife. (2005). Multivariate Determination of Free Fatty Acids and Moisture in Fish Oils by Partial Least squares Regression and Near-infrared Spectroscopy. Food Science and Technology. 38 (8): 821-828.

Eisenberg, H.S.' Y. Silberberg, R. Morandotti, and J.S. Aitchison. (2000). Diffraction management, Phys. Rev. Lett. 85, 1863.

Hassan H. E. and H.A. Badawy (2006). Visible laser for quality evaluation of sunflower oil. The $14^{\text {th }}$. Annual Conference of the Misr Society of Ag. Eng., "New Trends in Agricultural Engineering" 22 Nov., 2006. 823 - 837.

Lukesov, D., J. Dostlov, E. M. El -Moneim and M. K. Svrovs. (2009). Oxidation Changes of Vegetable Oils during Microwave Heating. Department of Food Chemistry and Analysis, Institute of Chemical Technology in Prague, Czech J. Food Sci. Vol. 27. Pp. 22.

Markley, K. S. (1990). Fatty Acids, Part 1, Inter science Publishers, New York, pp 499-607.

Robert, A. M., D. B. Johnston and K. B. Hicks. (2006). Influence of Moisture Content and Cooking on the Bench Scale Screw Pressing of Corn Oil. Crop Conversion Science and Engineering Research Unit, Eastern Regional Research Center, U.S. Dep. of Agric. 111: $(8-10)$.

Star G., E. R. Weinert and P. Urban. (2005). Discrete diffraction in an optically induced lattice in photo refractive media with a quadratic electro-optic effect, Department of Electrical Engineering, Szczecin 
Univ. of Technology, 7 th International Workshop on Nonlinear Optics Applications, Poland, 13(2) : 93-102.

\section{الملخص العربيى}

الكشف على جودة زيت الذرة المسخن باستخدام الضوء المرئى والغير مرئى المئ

حمدى على بدوى (r) ( )
حلمى السيد حسن (1) - (1)

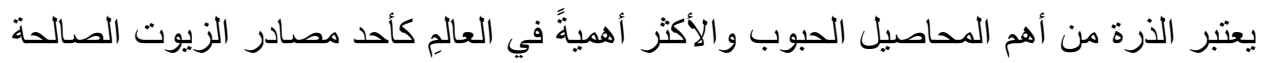

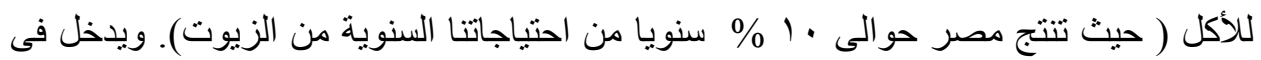

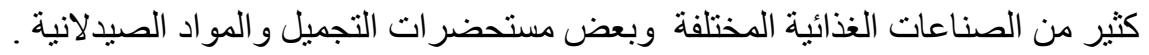

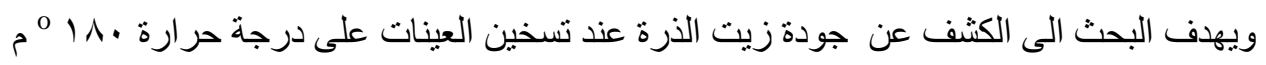

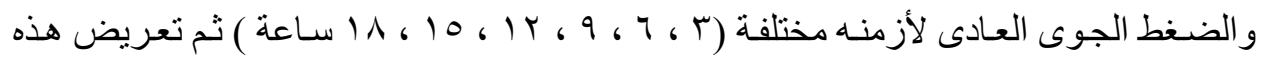

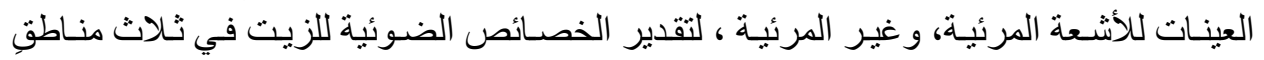

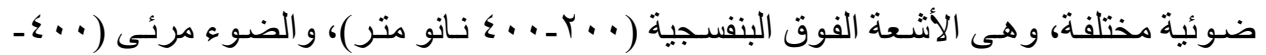

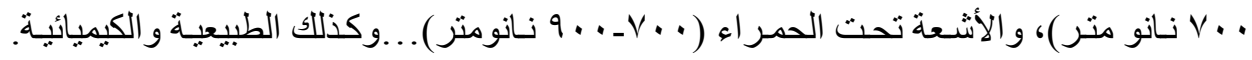

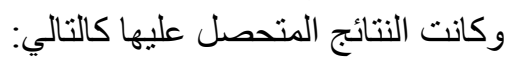

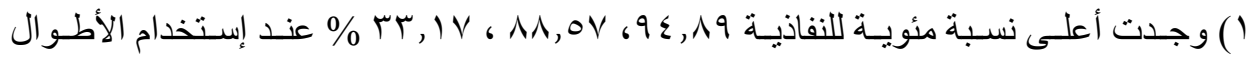

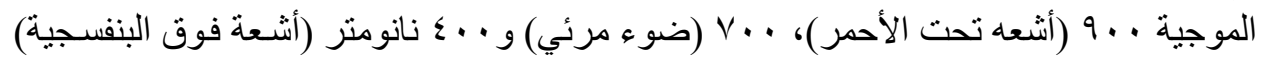

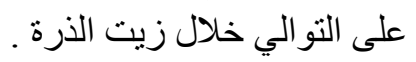

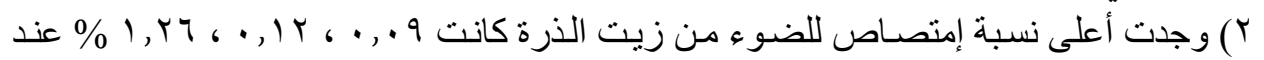

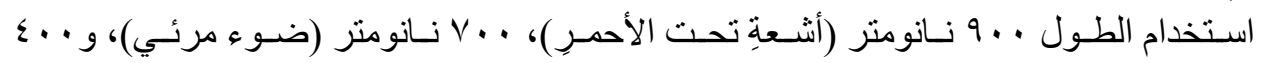

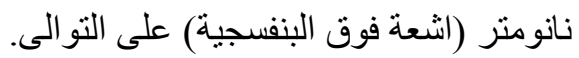

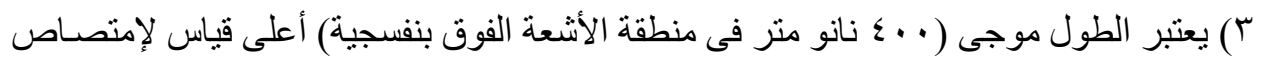
زيت الذرة بينما الطول الموجى ل . .

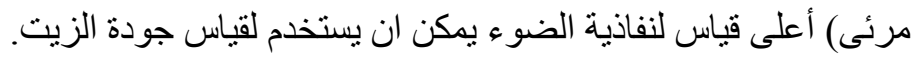

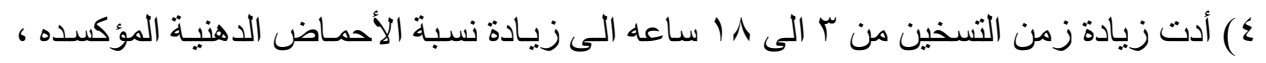

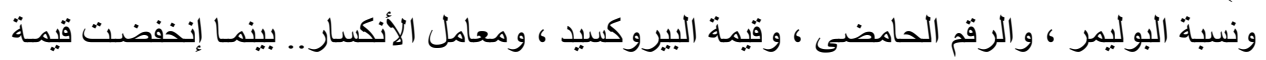

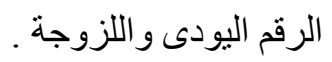

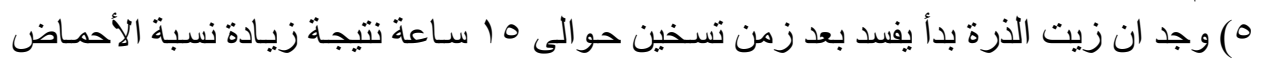

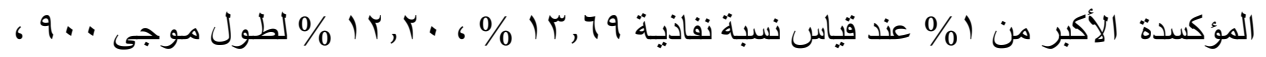

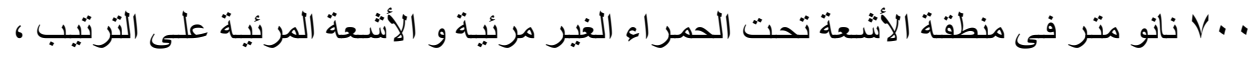

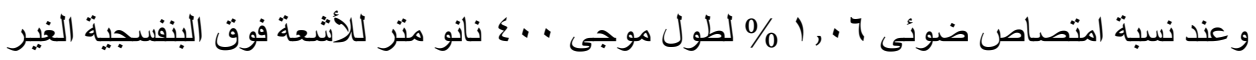

1ـ أستاذ مساعد تطبيقات الليزر فى الهندسة الزراعة ـ المعهد القومى لعلوم الليزر - جامعة

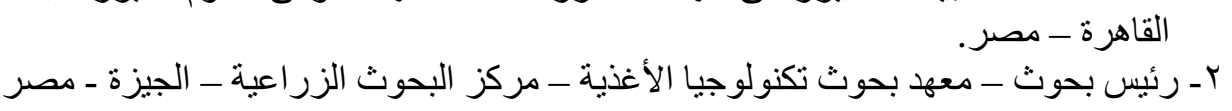

